\title{
LO QUE PERMANECE EN EDUCACIÓN ${ }^{1}$
}

\section{What Remains in Education}

\author{
Gregorio LURI \\ gregorioluri@gmail.com
}

Fecha de recepción: 24/09/2021

Fecha de aceptación: 23/11/2021

Fecha de publicación en línea: 01/03/2022

Cómo citar este artículo: Luri, G. (2022). Lo que permanece en educación. Teoría de la Educación. Revista Interuniversitaria, 34(2), 177-188. https://doi.org/10.14201/teri.27573

RESUMEN

Este texto plantea diversas cuestiones relacionadas con la antropología de la educación: el fenómeno del miedo en la escuela; las permanencias antropológicas en educación; el actual descrédito del conocimiento en pedagogía; la importancia de la herencia recibida y de la capacidad para mantener una gran conversación con las figuras de la cultura; el empeño presente en modificar el mundo de la vida; la dificultad que tiene el discurso de la escuela para integrar las exigencias de las nuevas tecnologías; la importancia del lenguaje en los maestros y el cuidado de sí como tarea educativa. Una de las tesis principales del artículo es que para educar es imprescindible reconocer las permanencias en el ser humano, aquello que nos hace ser lo que somos y que nos hace dirigir la atención a lo que queremos ser.

Palabras clave: Antropología de la educación; naturaleza humana; conocimiento de la educación; nuevas tecnologías; mundo de la vida; cuidado de sí.

1. Este texto es la transcripción, en formato de artículo, de la conversación pública mantenida, vía internet, con el profesor Gregorio Luri, el 24 de septiembre de 2021 dentro de la actividad «Diálogos sobre educación» organizada por la revista Teoría de Educación. Revista Interuniversitaria. Agradecemos al profesor Luri su generosidad para participar en esta conversación. Agradecemos a Enrique Alonso-Sainz la organización técnica. Transcripción: Irene Marchena Vaquero. Disponible en: https://revistas.usal.es/ index.php/1130-3743/dialogos 


\section{ABSTRACT}

This text raises various questions related to the anthropology of education: the phenomenon of fear at schools; anthropological stays in education; the current discredit of knowledge in pedagogy; the importance of the inheritance received and the ability to have a great conversation with the figures of culture; the present effort of modifying the world of life; the difficulty of the school discourse to integrate the demands of new technologies; the importance of language for teachers and self-care as an educational task. One of the main theses of the article is that in order to educate it is essential to recognize the permanence in the human being, what makes us what we are and what makes us direct our attention to what we want to be.

Keywords: Anthropology of education; human nature; knowledge of education; new technologies; world of life; self-care.

\section{El FENÓMENO DEL MiEdo EN LA ESCUELA}

Desde hace algún tiempo siento un gran interés por un fenómeno que me parece que es pedagógicamente muy nuevo (como todas las cosas nuevas, como todas las revoluciones importantes, llegan, según Nietzsche, a paso de paloma, mientras que miramos los fenómenos que meten mucho ruido). Me preocupa y me interesa mucho el fenómeno del miedo en la escuela. Hoy estamos educando a las nuevas generaciones en el miedo al futuro, no solamente por cuestiones climáticas, o todo lo que pueda suponer el antropoceno, sino con la sensación de que han llegado ya tarde a la búsqueda de soluciones y que, por lo tanto, tienen que asistir de manera pasiva a una especie de declive generalizado.

Este fenómeno es absolutamente nuevo porque si la escuela estaba para garantizar un futuro, ahora parece que de manera espontánea esté para temerlo. Esto hay que pensarlo bien, ojalá sea un epifenómeno que vaya a durar unos años y desaparezca, pero me da la sensación de que aquí hay algo más de fondo, porque ese miedo al futuro va acompañado de un fenómeno más amplio: un cansancio del hombre con respecto a sí mismo. Hoy está de moda, es de buen tono, criticar lo que se llama el antropocentrismo o la soberbia antropocéntrica. Es de buen tono romper todo aquello que sean límites, que te limite o que cree diferencias específicas entre el humano y el animal. Esto supone, de hecho, objetivamente, una rebaja de la manera como el hombre se ve a sí mismo, algo de una extraordinaria importancia. En el cristianismo, el ser humano era un ser tan especial que estaba por encima de los ángeles -por dignidad, por categoría o por excelencia-, y ahora lo estamos rebajando para que no haya diferencias con respecto a los no humanos.

¿Esto qué quiere decir? ¿Qué significa? Me he propuesto pensar en las dimensiones del miedo al presente, en nuestros miedos, en las dimensiones de esa vergüenza que tenemos. Yo creo que nos sentimos culpables porque no todas las promesas 
que la humanidad se hizo a sí misma con la Ilustración se han realizado, y hay un cansancio no de las promesas, sino del sujeto que hizo las promesas, y esto tiene dimensiones muy significativas e importantes. Quiero resaltar un hecho que me parece que antropológicamente sigue siendo muy relevante: al hombre se lo está criticando porque es incapaz de cuidar del todo, y esa crítica de su incapacidad para cuidar del todo no deja de reconocer su dignidad como cuidador del todo.

\section{LAS PERMANENCIAS ANTROPOLÓGICAS EN EDUCACIÓN}

En Pedagogía estamos viviendo -y lo digo con dolor- uno de los momentos más flojos, teóricamente hablando, de la educación, de las ciencias de la educación. Si miras la historia de la educación, de la Pedagogía, tradicionalmente, los grandes pedagogos han sido personajes públicos que intervenían en los debates públicos y que su opinión, su voz, era reconocida, después valorada en uno u otro grado. El caso más claro sería Natorp y todos los neokantianos alemanes, pero del mismo modo la escuela republicana francesa, ¿quién la construye, sino pedagogos con una dimensión pública extraordinaria? ¿Y la italiana? Nosotros, es cierto, dispusimos de esos pedagogos con esa experiencia, a mi modo de ver, tan ambigua y que aún necesita una reflexión rigurosa, que fue la Institución Libre de Enseñanza, pero es cierto que allí había pedagogos con una repercusión pública. Pero después todo eso ha quedado en una falta de ambición de la Pedagogía que percibo -especialmenteen un abandono de la reflexión sobre las causas finales de la educación -¿para qué educamos?- , y en un interés obsesivo por las causas eficientes del aprendizaje, por el cómo se aprende.

Un caso claro lo tenemos con las competencias, ¿quién puede estar en contra de las competencias? Ahora bien, si las competencias nos dejan sin espacio para la pura teoría, entonces, lo que tenemos qué es ¿̇una ganancia o una pérdida? La teoría quiere decir el disfrute de la propia comprensión de algo, la experiencia de que has estado luchando contra un problema, los interrogantes que nos acompañan de por vida, los problemas del conocimiento tratados cara a cara. Esto no los puedes abandonar. Algunos en EE. UU. me decían que también existen las competencias teóricas, y yo les dije: «Pues si existen las competencias teóricas yo ya no entiendo nada!

Hoy todos parecemos personajes que van corriendo detrás del viento del futuro esperando darle alcance, y no nos podemos parar porque si nos paramos nos va a llegar el pasado. Ahora nadie tiene miedo a que le digan que está equivocado, porque te puede contestar que es mi opinión; pero ya se ve como un agravio si le dices que está anticuado. Si tú te olvidas del pasado no solamente olvidas de dónde vienes, no solamente cercenas esa proyección natural de tu personalidad que es tu patria, no solamente ignoras el caudal cultural que ha llegado hasta ti y que te permite ser lo que eres, sino que sobre todo estas ignorando algo sumamente relevante: las permanencias antropológicas, que en el hombre no todo es nuevo. 
Por ejemplo, hay un modelo de infancia, el de Philippe Ariès, que creo que solo se mantiene hoy en las facultades de Pedagogía de nuestro país que sostiene que la infancia es una construcción sociológica. Hace falta ser un poco zopenco para no entender que los niños de todas las épocas nacen con un cuerpo que tiene límites y eso no está socialmente construido; hace falta ser bastante zopenco para no darse cuenta de que los niños de todas las épocas nacen con una característica común: nacen sin memoria, y eso no está socialmente construido. La negación, la incapacidad para ver las permanencias, nos hacen pagar un precio considerable porque si no las ves, no concedes valor a las permanencias y, entonces, solo te queda eso, como decíamos antes, la persecución del viento, a ver si alcanzas el futuro.

Por otra parte, como vamos tan corriendo detrás del futuro no logramos pensarlo bien. Por ejemplo, los economistas llevan desde hace unos años, unos cinco o seis, diciéndonos que no acaban de ver ese aumento disparado de productividad que nos prometieron que iría asociado a la introducción de las nuevas tecnologías. Mirando tanto el futuro estamos un poco despistados con el presente. Y a la Pedagogía le pasa igual: no veo, desde la Pedagogía, reflexiones ambiciosas sobre el presente. La reflexión pedagógica no está pasando precisamente por su siglo de oro.

\section{El ACTUAL DESCRÉdito DEL CONOCIMIENTO EN PEDAgogía}

El actual descrédito del conocimiento tiene dos dimensiones. Por una parte, diríamos una inflación del constructivismo que lleva a despreciar totalmente la objetividad del conocimiento, como si el objeto del conocimiento por sí mismo no nos impusiera unas específicas vías de acceso. Decía Balmes que conocer es reconocer en lo que hay exactamente lo que hay y solo lo que hay. Hoy hemos convertido en glamuroso el desprecio de las asignaturas cuando no son un capricho de nadie sino lo que permite el acceso al conocimiento específico: el acceso al concepto de número requiere un pensamiento específico, de la misma manera que el acceso a la crítica literaria requiere otro, y el acceso a la estética otro, y no es lo mismo analizar Madrid desde un punto de vista sociológico que desde un punto de vista cultural, que desde un punto de vista histórico, que desde un punto de vista geográfico. Por eso, cuando se nos dice que hay que buscar la transversalidad, conviene recordar que la transversalidad es aquello a lo que llegas después de dominar algunas asignaturas, cuando tú te das cuenta de que con la geografía no tienes suficiente y que necesitas también, por ejemplo, la economía. Debemos tener humildad frente al conocimiento porque la realidad nos impone determinadas vías de acceso. No se puede acceder así al todo sin la disciplina particular de conocimiento que impone una asignatura. Si no aceptamos esas vías acabamos en el capricho de creer que todo es como queremos que sea o como lo vemos y, al final, terminamos también con la frustración de que, en última instancia, la realidad siempre se reserva la última palabra.

Por otra parte, en el conocimiento hay una cuestión moral que a mí me interesa tanto o más que la anterior. Cuando Platón en la Academia hablaba 
del cuidado del alma, de la Epimeleia, básicamente lo que estaba haciendo es decirnos que tengamos contacto con el saber riguroso porque el saber riguroso es un medio de cuidar del alma. El contacto con los conceptos bien definidos, el contacto con los razonamientos que están bien estructurados y que te llevan con orden de las premisas a la conclusión, es un medio de cuidar del alma. Por decirlo de una manera un tanto exagerada: en las matemáticas también hay una educación emocional porque tú no puedes decir que esta suma es dos y pico porque es primavera sino porque unas premisas determinadas te llevan obligatoriamente a esa conclusión. Sin el respeto a la objetividad del saber acabas condenado a la defensa de las opiniones por el mero hecho de ser mías, y eso es una degradación, eso es la sofística, una degradación sobre todo de la democracia. Volviendo de nuevo a Platón, el cuidado del alma y el cuidado de tu comunidad van de la mano.

Cuando yo planteo en La escuela no es un parque de atracciones la defensa del conocimiento riguroso, lo que estoy diciendo es que el rigor en el conocimiento es la trascendencia de la carga subjetiva de un concepto para llegar a la carga objetiva. Cuando un niño pequeño piensa en "ciudad» si vive en Madrid piensa en Madrid, y si vive en Pamplona piensa en Pamplona, llegar al concepto de ciudad que no es ni ésta ni aquélla, ni la ciudad de los abuelos, es un proceso intelectual riguroso pero que te capacita para entrar en el dominio del conocimiento. Soy incapaz de entender por qué desde la Pedagogía seguimos, después de unos años que no nos han llevado a ningún sitio, despreciando el conocimiento, cuando además todos sabemos por nuestra propia experiencia que al buscar a un buen profesional, buscamos al que tiene conocimientos más rigurosos pues no es lo mismo el aprendiz que el experto.

Suelo contar una anécdota que me resultó muy violenta. Me invitaron a ir a una escuela de un barrio de gitanos de una ciudad importante, allá estaba todo el claustro. La directora comenzó a explicarme que en aquella escuela no les importaba dar conocimientos a los niños porque lo que pretendían era hacerlos felices. Yo salté y le dije que era lo más reaccionario que había oído en los últimos años porque el colegio tiene que suponer una posibilidad de salida, de trascendencia del barrio, después algunos lo cruzarán, otros se quedarán, pero si no les das a estos niños la posibilidad de salir del barrio, y salir del barrio quiere decir elevarse culturalmente sobre él para ver otras posibilidades y otros mundos, si no les das a esos niños esa posibilidad, ¿para qué sirve la escuela? Por eso yo cada vez insisto más en que la mejor definición de educación que conozco es la de mi madre que me decía: «Hijo mío, estudia para que puedas presentarte en cualquier sitio». Pues de eso se trata, si no te trasciendes a ti mismo sólo puedes tratarte a ti mismo ante el espejo que es el narcisismo; si trasciendes a tu familia quiere decir que puedes salir de tu familia y relacionarte con otras familias, pero lo que mi madre quería decir tenía también una carga moral muy fuerte: tienes que ser capaz de comportarte sin prepotencia ante el humilde y sin humillación ante el poderoso, pero para eso 
necesitas recursos y eso solo nos lo proporciona el conocimiento. Por eso insisto en la dimensión moral del conocimiento, en la dimensión afectiva del conocimiento.

\section{Lo QUe EL SISTEMA PEDAGógICO NO DÉ, LO VA A SUPLIR EL MERCADo}

A medida que estamos bajando el nivel de las escuelas, se está incrementando el presupuesto que las familias dedican a actividades formativas extraescolares. En los últimos veinte años se ha multiplicado por cuarenta este presupuesto. ¿Y quién puede seleccionarlas y pagarlas? A medida que estamos bajando el nivel de la escuela, estamos efectivamente equiparando a todos en la titulación, pero no en el conocimiento. Por eso, para las familias que puedan proporcionársela a sus hijos se está volviendo a la figura del profesor particular, que hacía unos años estaba casi desaparecido y a la búsqueda de academias como, por ejemplo, Smartick, un portal de matemáticas en Internet que está revolucionando la Pedagogía. Lo que el sistema pedagógico no dé, lo va a suplir el mercado. Debemos dejar claro que cuando entramos en la escuela, al menos aparentemente, todos somos iguales, frente al mercado no; y, por lo tanto, bajo ese discurso tan buenista de la equidad, estamos fomentando desigualdades.

En Andalucía tenemos desde el 2009 un porcentaje de alumnos que están en los dos niveles inferiores de PISA, es decir, en aquellos niveles que PISA reconoce que no te capacitan para tener las competencias mínimas imprescindibles para enfrentarte al mundo actual. El porcentaje de niños andaluces que están en los dos niveles ha sido a lo largo de los años el $31 \%$, el $23 \%$, el $27 \%$, el $30 \%$, es decir, uno de cada cuatro niños aproximadamente está en los dos niveles. Creo que debería ser un motivo de escándalo que desde 2009 no se hayan mejorado estos resultados. El otro día lo plantee en Córdoba y me dijeron que es que yo era ciego para las causas y siempre contesto lo mismo: "Mira a tu alumno cara a cara y dile que como tu nivel socioeconómico es ' $x$ ' tus resultados en matemáticas serán 'y'”. ¿Qué la situación socioeconómica condiciona? Es obvio que condiciona, ahora bien, ¿que determine? Eso depende de la actuación de la escuela.

\section{LA GRAN CONVERSACIÓN}

No hemos construido este mundo de la nada para habitar en él como si fuéramos seres adánicos. No lo somos. Vivimos en mundos de segunda mano y además vivimos alrededor de voces que están cruzándose entre ellas y que son de figuras muertas.

Creo que una de las dimensiones de una persona culta, una de las características de una persona culta es ser capaz simplemente, por ejemplo, de que cuando va paseando por el Madrid de los Austrias, reconoce las voces que le están hablando desde cada piedra aunque no las entiende todas o solo oiga un rumor de fondo. El que pasa por el Acueducto de Segovia o por la Mezquita de Córdoba y no ve más 
que piedras y lo único que se le ocurre decir es "qué bonito", pues entonces está ausente, es sordo para lo que yo llamo "La gran conversación", la que mantienen entre sí las grandes figuras de la cultura.

Europa se caracteriza porque no tiene ningún libro que sea intocable. Ningún libro es intocable desde que Spinoza somete a un análisis crítico a la Biblia, bueno podríamos decir antes, desde que Erasmo somete a análisis crítico tanto a los evangelios como a las epístolas, y además cuando lo hace dice que esto no tiene sentido. No hemos tenido en Europa ningún libro intocable porque la verdad está por encima. Por eso, lo esencial en Europa es la búsqueda de la verdad en diálogo. Cada uno dialogamos con diferentes voces. A lo largo de nuestra biografía unas van creciendo y otras van disminuyendo. En mi caso algunas se mantienen fijas como, por ejemplo, Platón y Esquilo. Platón es mi contemporáneo porque encuentro en él ideas, reflexiones, palabras, que son de utilidad para entender mi presente. Si yo puedo leer en los versos de una poeta lesbiana del siglo VI a. C., en Safo, palabras que me emocionan sin ser ni griego, ni vivir en ese siglo, ni ser lesbiana, esto quiere decir que Safo es mi contemporánea. Volviendo a leer el Quijote he descubierto que Cervantes es también mi contemporáneo. Si esto es así, si los antiguos o al menos algunos de esos antiguos son tus contemporáneos, entonces hay que rebajar un poco los humos del presente porque tendemos, con un orgullo un poco infatuado, a considerarnos legitimados para enjuiciar, desde el presente, a todo el pasado en función de la proximidad o lejanía que tienen con respecto a nuestros prejuicios.

Yo lo planteo así. Si Platón de verdad me ayuda a entender el presente, entonces el historicismo hay que revisarlo, pero también el constructivismo. Cuando Platón, por ejemplo, define la democracia como una teatrocracia en la cual son los espectadores los que deciden cómo ha de desarrollarse la escena, ¿está describiendo a la Grecia del siglo IV o está describiendo la España actual? Cogemos libros a veces con miedo a que nos decepcionen, frente a un clásico eres tú el que tiene miedo de decepcionarlo porque son figuras mucho más grandes que tú.

\section{REIVINDICANDO LO IMPERFECTO, LO NORMAL Y CORRIENTE}

Creo que lo que caracteriza al presente es lo que decíamos antes, esa inseguridad del hombre con respecto a sí mismo. Por una parte, sentimos que los ideales de la Ilustración no se han realizado y, por otra, nos negamos a que no se realicen. Si para Lenin la revolución era el instrumento de modificación, nosotros nos empeñamos en un fenómeno muy interesante: en modificar el mundo de la vida.

Husserl es otro de mis contemporáneos. (Como pedagogo era un ser muy curioso: llevaba a su mujer a sus clases y la sentaba en la última fila. Al finalizar cada clase su mujer le decía quién se había distraído y quién había hablado). Me interesa la teorización de Husserl del mundo de la vida, esa tesis que tiene tan fuerte de que las ciencias por muy necesarias que sean son una reducción específica del mundo de la vida. Las matemáticas son necesarias cuando tú reduces el mundo de 
la vida a una determinada perspectiva sobre un objeto, perspectiva que es la que te impone el tipo de conocimiento que requiere ese objeto. Pues bien, estamos asistiendo a todo un asalto a la espontaneidad del mundo de la vida en todas sus dimensiones, por ejemplo, en el lenguaje todo aquello que hasta hace poco lo pronunciábamos con normalidad ahora resulta que es motivo de sospecha, todas aquellas relaciones que hasta hace poco eran relaciones normales ahora también resulta que son motivos de sospecha. Pero creo que hay algo más en ese asalto a la espontaneidad del mundo de la vida y que, por cierto, he encontrado en el filósofo coreano Han: te vienen a decir que si te lo estás pasando bien entonces eres culpable porque eres cómplice de los males del mundo; si te lo estás pasando bien entonces eres una persona alienada que está sometida a los discursos dominantes, es decir, eres una construcción social al servicio de no sé qué intereses espurios. Parece que hay que pasarlo mal y que hay que estar denunciando absolutamente todo para ser un concienciado.

A todos los que se empeñan en cultivar este asalto a la espontaneidad del mundo de la vida no se les ocurre pensar que el ser humano es mucho más débil y frágil de lo que nuestras teorías dicen de él. Ese ser humano frágil necesita entre, otras cosas, de la compañía de rituales, de tradiciones, de acuerdos que no se necesitan explicitar con los demás, de aquello que decía Chesterton cuando está reivindicando la vida normal y que para mí es lo más revolucionario: «la risa, el matrimonio y la cerveza». Si renunciamos a "la risa, el matrimonio y la cerveza", estamos renunciando a un mundo que sea humano. Por eso ese asalto al mundo de la vida que decíamos antes me parece despiadado. En nuestro tiempo lo más urgente es decirle al ciudadano normal y corriente que tiene razón en sus prejuicios, que no permita que nadie ajeno a él venga a decirle lo que tiene que pensar, con qué se tiene que reír, qué tiene que beber, qué tiene que comer..., dejémoslo que vaya construyendo su vida a partir de los elementos que tiene alrededor. Una cosa es ser maestro de escuela y otra cosa es ser el maestro de escuela de la sociedad, ya hay demasiados maestros de escuela de la sociedad. Practiquemos la humildad frente al mundo de la vida, si el matrimonio con todos sus límites lleva tanto tiempo perdurando, por algo será. Por eso defiendo tanto a las familias imperfectas, la sensatez de la familia imperfecta, y defiendo tanto la sensatez del hombre normal y corriente. Además, si tuvieran algo mejor que ofrecer a "la risa, el matrimonio y la cerveza»...

\section{7. ¿TIENE LA ESCUELA UN DISCURSO PROPIO QUE LE PERMITA INTEGRAR LAS NUEVAS TECNOLOGÍAs?}

Antes de la pandemia asistí en Madrid, en Ifema, a una especie de congreso sobre nuevas tecnologías y educación. Yo tenía preparado mi speech de quince minutos pero dio la casualidad de que la persona que me precedió era una alta directiva de una de las empresas tecnológicas más potentes del mundo. Nos describió el futuro y nos dijo que las cosas iban por aquí, que ya estamos en la cuarta 
o la quinta revolución. Al oírla llegué a la conclusión de que tenía que guardar mi texto en el bolsillo porque lo que me parecía urgente decirle era lo siguiente: «Señora, ¿por qué demonios cuando las nuevas tecnologías nos hablan del futuro siempre lo ven del color de sus planes estratégicos?». Y esto está bien porque esas empresas tienen que rendir cuentas a sus accionistas y, por lo tanto, su obligación es vender, crecer, etcétera, pero ¿la escuela está para hacer suyo de manera inmediata todos esos discursos? ¿No deberíamos ser un poco más calmados? Además, desde un punto de vista incluso económico, es imposible estar al día porque te compres lo que te compres a los cuatro días se convierte en cacharrería. Pero lo que me importa es: jtiene la escuela un discurso propio que le permita integrar las nuevas tecnologías en ese discurso o, como carece de discurso, se está rindiendo a las nuevas tecnologías porque le parece que la tecnología le está ofreciendo un discurso ideológicamente neutral?

Si hablamos de nuevas tecnologías ya no hablamos de fines de la educación, ya no hablamos de valores, de virtudes, de nada de esto, sino de que hay que actualizarse y parece que sea un discurso ideológicamente neutro. Lo que me preocupa es que el discurso pedagógico no es suficientemente potente para integrar dentro de su praxis y de su teoría una reflexión sobre las nuevas tecnologías, por lo que se está rindiendo a ellas.

El hombre es un ser tecnológico, no podemos vivir sin tecnologías. ¿Un hombre no diseñado cómo sería? ¿Que no se cortase el pelo, que no se cortase las uñas? Un hombre al que no se le enseña a caminar de pie, ¿cómo sería? Vivimos en entornos tecnológicos y somos seres tecnológicos, por eso insisto en que las tecnologías son básicamente prótesis antropológicas que amplifican lo que ya somos para bien y para mal. Si te interesa la poesía romántica letona, que no sé si existe, pues tienes seguro en Internet a los poetas más significativos del romanticismo letón; si te interesa el arte etrusco tienes posibilidades de llegar a artículos, a centenares de artículos sobre el arte etrusco sin necesidad de gastarte una fortuna en libros; pero si te interesa la pornografía también tienes más posibilidades que nunca de acceso a la pornografía o cómo construir bombas o cómo utilizar un cuchillo para descuartizar a una persona sin que sangre demasiado. En Internet lo tienes todo, está la información sin catalogación y lo que nos importa es el criterio para convertir la información en conocimiento y ese criterio no te lo proporciona Internet.

Rendirse a las nuevas tecnologías es rendirse a las prótesis sin darte cuenta de que amplifican lo que ya eres. De tal modo, que si no te preocupas por lo que eres, entonces, te están amplificando el vacío que eres y, esto es lo preocupante, pasas de una cosa a otra intentando llenar ese vacío con experiencias digitales que lo único que hacen es aburrirte enseguida por lo que necesitas pasar a otras.

Es más urgente que nunca una reflexión antropológica que nos permita entender lo que somos para poder ver claramente en el uso de las nuevas tecnologías si están amplificando o restringiendo lo que ya somos. 


\section{LO QUE ERES Y LO QUE PUEDES LLEGAR A SER: PERMANENCIA Y CUIDADO DE SÍ}

Es muy urgente que reconozcamos si el ser humano es un ser de temporada o un ser de permanencias. Eso cambia totalmente la perspectiva: si el ser humano es un ser de temporada, ¿para qué educar en el futuro si no sabemos cómo será? ¿Qué garantía tenemos de que dentro de veinte años se mantenga aquello que llamamos competencias y educación competencial? Si nos atrevamos a mirar el mundo tal y como nos aparece, descubriremos si hay o no permanencias y, si las hay, en ellas, se encuentra aquello que es el ser humano.

Desde hace un tiempo estoy reivindicando -sin ningún complejo- un término esencial en la cultura occidental que es el concepto de alma. No lo utilizo en un sentido religioso sino filosófico tal y como se hizo hasta Boecio. El alma yo la defino de esta manera: es el ámbito en el cual lo mejor que puedes llegar a ser se dirige a lo que eres. ¿Y cómo sabes qué es lo mejor que puedes llegar a ser? Porque parcialmente ya lo hemos sido. Nosotros tenemos experiencias parciales fragmentarias de nosotros mismos, de las que nos sentimos orgullosos y tenemos experiencias fragmentarias de nosotros mismos de las que sentimos vergüenza. Como no podemos ser morales fragmentariamente -Kant tenía razón-, entonces el reto es crear una imagen uniforme de nosotros mismos, no en función de las ideas, sino en función de lo mejor que hayamos sido, esa reflexión personal sobre tu propia experiencia.

Uno de los filósofos más voluntariamente incomprendido de nuestro tiempo es Foucault. Si bien en sus primeras obras reflexiona sobre el poder, en las últimas lo que están haciendo es reivindicar la Epimeleia, el cuidado de sí, y apoyándose en Nietzsche, el reto de hacer de tu vida una obra de arte. La responsabilidad sobre el cuidado de uno mismo no se la podemos alquilar ni ceder a nadie porque entonces somos sus siervos. Esto es lo que nos concede dignidad, pero para ello tenemos que creer que somos algo más que un ser de temporada.

Hace poco participé en un debate en Madrid hablando de la posibilidad de pasar sin suspensos que permite la nueva ley de educación. Señalé que a mí eso me preocupaba menos que la cuestión que me parece más esencial, más importante: llevamos ya un cierto tiempo intentando liberar al alumno de responsabilidades sobre sí mismo, lo que pone de manifiesto una determinada antropología. No estoy queriendo decir que a un niño de cuatro años le tengamos que exigir muchísimo, le tenemos que exigir menos que a uno de siete y al de siete menos que a uno de doce, pero a uno de catorce, de quince, de dieciséis ya se le puede exigir, yo diría que incluso al de siete se le pueden exigir cosas. Al asumir que eres responsable o al menos corresponsable de tu diálogo interior que es el que importa, de tu diálogo interior entre lo mejor que puedes llegar a ser y lo que eres, alcanzamos otra dimensión, otra profundidad, en nuestra propia vida y en nuestro entorno.

A mi modo de ver, las teorías humanas se evalúan bajo este criterio: ¿esta teoría me concede más profundidad o no? ¿Le concede más profundidad a mi ser y a mi 
mundo o se la quita? Si restamos la responsabilidad sobre nosotros mismos estamos disminuyendo la densidad del mundo humano.

\section{LA TRANSMISIÓN ES LENGUAJE: HABLA, HABLA MUCHO Y HABLA BIEN}

Hace tiempo llegué a la conclusión de que para muchos docentes hablarles de transmisión era como hablarles de metafísica. He cambiado el discurso porque no tiene sentido que te estés dirigiendo a los docentes y no te entiendan. Ahora prefiero hablar de vocabulario.

Nuestra cultura se manifiesta en nuestro lenguaje. El lenguaje es nuestra cultura en acto. Hemos de ser conscientes de que sea la que sea nuestra formación, sean las que sean nuestras ambiciones, sean los que sean nuestros proyectos de vida, la riqueza del lenguaje que empleamos ante los niños es un elemento esencial no sólo de su formación, sino de equidad porque con ese lenguaje, mejor dicho, ese mismo lenguaje, es la única vía realmente efectiva que tenemos de compensar las diferencias familiares.

Yo creo que Bernstein, el psicolingüista, tenía razón cuando señalaba algo que es así de sencillo: hay niños que cuando llegan a la escuela se encuentran con el lenguaje de su casa porque ya tienen un lenguaje familiar sofisticado, por lo que en la escuela están reforzando el lenguaje de casa y en casa están reforzando el lenguaje de la escuela. Pero también hay niños que cuando llegan a la escuela -y esto se ve especialmente de manera muy clamorosa a partir de los diez, once y doce años-, tienen que traducir el lenguaje académico al lenguaje familiar, dándose una pérdida notable; con lo cual la escuela falla totalmente en compensar las diferencias familiares.

El principal deber deontológico, el primer principio deontológico de un maestro debería ser: «utiliza un vocabulario amplio, complejo y sistematizado, habla, habla mucho». Los niños de dos años, como promedio, comienzan a decir palabras de dos frases "mamá agua", "quiero pis", y lo consideramos una gran conquista, pero ese mismo niño cuando canta utiliza palabras de tres y hasta de cuatro frases. Esto es el milagro del progreso, por lo tanto, vamos a enseñarle muchísimas canciones pero no cualquier canción, vamos a utilizar canciones en las que la semántica y la sintaxis cumplen un papel relevante porque la transmisión no deja de ser lenguaje en acto.

\section{LAS TRES REFLEXIONES ANTES DE ENTRAR EN CLASE}

Otro deber del maestro es ser optimista. Bajo ningún concepto podemos caer en el pesimismo. Frente al pesimismo de los hechos, siempre el optimismo de la voluntad, siempre, porque estamos trabajando con materias muy delicadas. Cuando hablo a los maestros les suelo decir que tienen que pensar que en su nómina, en su salario, hay una parte que se la pagan por ser profesional y otra moral, que se 
la pagan por ser optimista. Esta cuestión es fundamental y como todas las importantes va más allá de la Pedagogía porque apunta a cómo hacer de ti un referente.

En realidad, no se trata de utilizar grandes palabras ni grandes gestos, se trata de aprender a entrar en clase. Hace tiempo descubrí que para modificar la disciplina de un centro más que grandes proyectos lo que es imprescindible son las pequeñas palabras: "gracias", "por favor", "perdón" ... que tienen un poder extraordinario. Pues bien, también descubrí hace mucho tiempo que hay tres reflexiones que viene bien que nos las hagamos antes de entrar en clase. La primera es pensar que es muy probable que allí dentro haya una persona más inteligente que nosotros y aunque esa inteligencia no esté despierta todavía, nos va a juzgar con criterio. La segunda es pensar que es muy probable que allí dentro haya una persona moralmente superior a nosotros, es decir, con una conciencia y con un sentido del deber. Lo vamos a tener delante sin saber cuál es. Sabemos cuáles son los más espabilados pero no quién tiene esa capacidad de reflexión moral. Y la tercera es pensar que es muy probable que allí dentro esté una persona esperando que un adulto le diga la palabra adecuada que le permita cambiar de trayectoria, y tampoco sabemos cuál es. 